\title{
LOS PROBLEMAS DEL AHORRO Y DE LA INVERSIÓN
}

Por el doctor E. G. BARRETO

El objeto fundamental de la actividad económica es la producción de bienes y servicios que permitan satisfacer las necesidades humanas. La producción, así, puede ser de artículos de consumo y de bienes de inversión, dando origen dicha actividad productiva a la renta nacional. Esta renta puede gastarse en bienes de consumo y de inversión 0 ahorrarse. En este último caso la renta ahorrada está representada por la parte de la renta que no es gastada. Los bienes de consumo deben ser adquiridos por los consumidores, y los de inversión por los que acumularon ahorros.

Para que la actividad económica se mantenga en los países de alto desarrollo el volumen de las inversiones debe ser igual a la parte de la renta que se retira como ahorro. Si hay desequilibrio en un período determinado, la renta en el período siguiente será mayor o menor, ya que habrá la tendencia a la igualación del ahorro y la inversión.

Una renta de 100 puede provenir de la producción de 80 de artículos de consumo y 20 de artículos de inversión. Si de dicha renta de 100 se gasta 80 en artículos de consumo y 20 se ahorra o atesora, quedará sin venderse, los 20 producidos de artículos de capitalización; para que esto no suceda y continúe la producción normal de artículos de capitalización debe realizarse una inversión de 20 , que equivalga a la parte de la renta retirada mediante el ahorro y no invertida. Si en vez de invertirse como 20 sólo se invierte como 10 quedará un valor de 10 de mercaderías de inversión no vendidas que incrementarán forzosamente los stoctes y obligarán al productor a reducir la producción al ver que los productos no se venden. Al reducirse la producción en 10, en un período siguiente la renta será en vez de 100 sólo 90 , o sea 80 de artículos de consumo y 10 de artículos de inversión, en forma tal que el ahorro igualará a la inversión.

Al reducirse la demanda real de artículos de consumo o de inversión, ello tenderá a reducir la producción y la renta en aquellos artícu- 
los cuya demanda ha disminuído, ya que el que produce algo es para venderlo, y si no hay quien lo compre dejará de producirlo o reducirá la producción de dichos artículos.

En vez de la interpretación dinámica que hemos analizado más arriba el economista Keynes da una interpretación estática a la igualdad de ahorro e inversión. Al no consumirse parte de la renta mediante el ahorro, simultáneamente se produce una inversión equivalente a la suma ahorrada, inversión representada por el aumento correspondiente en los stocks al dejar de gastarse la parte de la renta que se ahorra. O sea que el ahorro de una suma determinada produce automáticamente y en el mismo período la inversión equivalente por la acumulación correspondiente en los stocks.

La interpretación dinámina tiene la ventaja que considera el factor de atesoramiento. En efecto, la suma ahorrada o se invierte o se mantiene atesorada en forma líquida, en cuyo caso la suma atesorada en el período anterior más la suma ahorrada del período siguiente, si se invierten en dicho período, pueden resultar mayores a la suma ahorrada, produciéndose una desigualdad temporal entre el ahorro y la inversión, que es la forma corriente y dinámica como actúan ambos factores en la economía. Cuando se ahorra más de lo que se invierte hay atesoramiento; cuando se invierte más de lo que se ahorra hay desatesoramiento. Al realizarse una mayor inversión que el ahorro en un período determinado ello aumentará la renta y el ahorro del período siguiente hasta que el nuevo ahorro proveniente de la mayor renta, igualen a la mayor inversión. Asimismo, al realizarse un mayor ahorro que inversión, ello tiende a reducir la renta y el ahorro en el período siguiente hasta que iguale el monto de inversión.

Es precisamente esta diferencia temporal entre la inversión y el ahorro lo que mejor explica el estancamiento, el retroceso o el progreso en la economía. Un aumento de la inversión sobre el ahorro en un período determinado estimulan el progreso a condición que no haya «ocupación plena» en los países de alto desarrollo, y se pase por un período de «ocupación deficiente» sin tendencia inflacionista, en los países de escaso desarrollo. Para mantener la ocupación plena, el volumen de inversión debe corresponder al de ahorro; y, en caso de inflación, el volumen de ahorro debe exceder el de inversión normal.

Por supuesto que la igualdad de ahorro e inversión no se refiere a los casos individuales, ya que no siempre el que ahorra invierte suma igual, sino al conjunto del país o sea a la suma total de ahorros e inversiones dentro del país. Asimismo, dentro de un concepto dinámico, el ahorro y la inversión en vez de decirse que son iguales puede decirse que tienden a ser iguales a través del tiempo. En ambos conceptos 
hay, como hemos dicho, sólo diferencias metodológicas. Además, no debe confundirse ahorro con atesoramiento. El atesoramiento está constituído por la parte del ahorro que no se invierte por los particulares o las instituciones de crédito en bienes de inversión; y, dentro del conjunto de la economía está constituído por la diferencia entre el monto total del ahorro y el monto total de la inversión, si el ahorro resulta mayor que la inversión en un período dado habrá atesoramiento, si la inversión es mayor habrá desatesoramiento.

Analizados estos conceptos generales veamos los problemas del ahorro y la inversión en los países de ocupación deficiente.

\section{LOS PROBLEMAS DEL AHORRO Y LA INVERSIÓN EN LOS PAÍSES DE OCUPACIÓN DEFICIENTE}

Las cifras del producto nacional y de la renta permiten apreciar el monto de las inversiones y de los ahorros del país, que desempeñan papel fundamental en la situación económica y en su desarrollo. El proceso del ahorro e inversión, que constituye lo que técnicamente se denomina el proceso de formación de capital, es el motor principal de la actividad económica.

La formación de capital varía a través del tiempo, de la estructura económica de los diversos países, según sean éstos de alto desarrollo o de ocupación deficiente, y de la situación de crisis de inflación o deflación por la que pasa la economía.

En los países poco desarrollados se necesita un porcentaje relativamente mayor de inversión neta que en los más desarrollados, ya que en aquéllos son mayores los recursos por explotar y las obras por realizar que en los que ya han logrado, a través del tiempo, un progreso en ese sentido. En éstos, en cambio, por el mayor volumen de inversiones ya realizadas los gastos de reposición son considerables y, en períodos normales, representan cerca de los $2 / 3$ del ahorro bruto.

Los porcentajes de ahorro e inversión brutos y netos sufren violentas variaciones, tanto en los países altamente industrializados como en los de ocupación deficiente en las erisis cíclicas de inflación o deflación. Así por ejemplo, en los Estados Unidos de América el ahorro representó el $20 \%$ del producto nacional bruto en la época próspera de 1929, mientras en 1932, en plena crisis de deflación sólo llegó al $5 \%$, resultando negativo con relación a las depreciaciones y agotamiento del equipo productivo. Del $20 \%$ del ahorro bruto en períodos de prosperidad correspondió el $66 \%$ a las provisiones para reposición y el $33 \%$ restante para ahorro neto. Durante la crisis de $1930 / 33$, la consumación de capital excedió el porcentaje de formación de capital para nuevas inversiones, habiendo existido lo que se denomina «desinversión». 
Tres aspectos fundamentales caracterizan el ahorro y la inversión internas en los países insuficientemente desarrollados: la baja renta y ahorro per cápita de su población; la forma desigual de distribución de las rentas, que afecta la distribución y monto de los ahorros; y la insuficiencia de las instituciones y mercado de capital que canalizan los ahorros hacia la inversión.

Ya hemos explicado las causas principales de la baja productividad, renta y ahorro per cápita en los países insuficientemente desarrollados, en los que vive cerca del $80 \%$ de la población del mundo; asimismo hemos visto la gran desigualdad en la renta per cápita que existe entre los países más desarrollados y los de insuficiente desarrollo, habiendo a su vez dentro de éstos diversas categorías.

Para que haya progreso, el aumento anual de la inversión neta debe sobrepasar el porcentaje de aumento de su población, porque de lo contrario habrá estancamiento o retroceso en la renta real per cápita y en el volumen de los ahorros, bajando por consiguiente el nivel de vida de la población. L to mismo debe decirse de la necesidad de aumento en la superficie cultivada, en la producción alimenticia, en la edificación, etc. Si estos factores no se desarrollan conjuntamente con el aumento de la población se presentarán los problemas de escasez, estancamiento y retroceso. La baja capacidad productiva se debe principalmente a la falta de tecnificación en grandes sectores de la producción y a sus formas primitivas de trabajo. En los países de ocupación deficiente el sector agrícola absorbe la mayor parte de la población, no obstante que el rendimiento medio per cápita es más bajo, en conjunto, que el originado en otras actividades productivas. Dicha baja productividad se explica también por los pocos esfuerzos que se hacen para tecnificar la producción de esos sectores. Aún los países desarrollados, como Estados Unidos han realizado los mayores esfuerzos en la postguerra para aumentar la productividad agrícola. Durante el período de guerra y postguerra en Estados Unidos se invirtió cerca de 8 mil millones de dólares para aumentar la cantidad de tractores y otros implementos mecánicos cuyo número casi se ha duplicado en ese período, permitiendo una mayor productividad del $40 \%$ con relación al nivel de preguerra, y menor empleo de mano de obra que ha sido sustituída por el factor máquina.

Igual cosa ha sucedido en Canadá y en otros países.

En los países insuficientemente desarrollados el mayor porcentaje de la población tiene rentas reducidas, que las obsorbe en su mayor parte el consumo, que resulta todavía deficiente, no quedando casi margen para acumulación de ahorro en dichos sectores, concentrándose sólo en un porcentaje relativamente reducido de la población. En los países más desarrollados el alto nivel promedio per cápita de la renta permite un ahorro más diversificado, y por consiguiente, 
un mayor volumen y en sectores más variados. Cuando el ahorro se concentra en sectores reducidos que tienen determinada actividad productiva la inversión, por lo regular, se realiza en la misma industria o se esteriliza si la inversión en ella resulta excesiva. Hay así poca tendencia a la diversificación de la inversión. En cambio cuando los ahorros están diversificados y hay las instituciones de inversión o mereado de valores convenientes, las inversiones tienden a diversificarse en las diversas actividades productivas.

Según se manifiesta en el estudio «Métodos de Financiamiento del Desarrollo Económico de los Países Insuficientemente Desarrollados», publicado por las Naciones Unidas, el ahorro neto en los países desarrollados como Gran Bretaña, Canadá, etc., alcanza porcentajes del 10 al $12 \%$ de la renta nacional, mientras en los menos desarrollados como India, Chile, etc., los porcentajes varían del 2 al $5 \%$. El ahorro per cápita en los menos desarrollados representa aproximadamente un valor medio equivalente al $5 \%$ del ahorro per cápita de los países más desarrollados.

Esta diferencia del ahorro nacional, y sobre todo su irregular distribución, hacen que el ahorro voluntario sea relativamente reducido y que el ahorro forzoso se vea limitado por la baja renta de dichos sectores que sólo permite un consumo subnormal.

No obstante que los países insuficientemente desarrollados tienen gran necesidad de incremento en las inversiones, la limitación en la formación de ahorros por la baja renta de grandes sectores de su población, impide la diversificación de los ahorros y de la inversión, haciendo poco eficiente, en la práctica, el estímulo del ahorro voluntario en dichos países y muy limitada la utilización de los medios de ahorro forzoso, ya que al reducirse aún más el poder de consumo y el nivel de vida hay el peligro de una mayor reducción en la productividad y de que se produzcan trastornos sociales.

Se está así ante un círculo vicioso. No hay progreso porque no hay inversiones suficientes; y no hay inversiones suficientes porque no hay ahorro suficiente ni diversificación y también, en algunos casos, porque se desalienta mediante medidas impositivas exageradas o prácticas inflacionistas la formación normal de capital privado.

El desarrollo normal del país debe basarse en el proceso de formación de capital o sea en el ahorro e inversión nacional y en el estímulo de otras inversiones. Pero, en muchos países el escaso ahorro nacional no se utiliza suficientemente o permanece atesorado por la falta de organismos de inversión o mercados de capital que canalicen el ahorro hacia la inversión. Los organismos de inversión y los mercados de capital han sido y son factor fundamental de desarrollo en países como Estados Unidos, Canadá, Gran Bretaña, Argentina, Brasil, etc. Cuan- 
do se carece de un mercado de dinero y de organismos de inversión, el ahorro tiende a orientarse a las operaciones especulativas de corto plazo en vez de a las inversiones reproductivas.

\section{EL PROCESO AUTOGENERADOR DE FORMACIÓN DE CAPITAL}

El nivel de productividad y renta depende de la estructura y caracteres de la economía. Para elevar la renta real, o sea incrementar en sus bases el proceso de formación de capital, se requiere hacer previamente el análisis de la estructura económica del país y de las causas generatrices internas y externas que determinan dicho nivel de renta y productividad; sólo entonces ha de ser posibles apreciar las variaciones de largo plazo que permitirían aumentar dicha capacidad productiva y renta real. Asimismo, al hacer dicho análisis debe diferenciarse las oscilaciones circunstanciales de valor, acompañantes de las crisis de inflación o deflación, de las tendencias estructurales de largo término. Hay que saber así en qué etapa se está; a qué grado de desarrollo se puede aspirar y cómo lograrlo.

El objetivo fundamental de la política económica y financiera en los países de alto desarrollo ha sido en las últimas décadas alcanzar y mantener niveles de ocupación plena y una distribución equitativa de las rentas. Sin embargo, en muchos países el logro de estos objetivos ha acentuado la tendencia inflacionista.

En los países insuficientemente desarrollados el objetivo fundamental de largo término es aumentar la productividad y la renta real per cápita, y estimular el proceso autogenerador de formación de capital que permita una mayor explotación de los recursos naturales y un standard de vida más alto. En estos países no basta que haya ocupación plena en el sentido que se emplea este término en los países más desarrollados, sino que debe haber simultáneamente para que exista progreso real mayor productividad y renta per cápita.

\section{EL AUMENTO DE LA PRODUCTIVIDAD Y RENTA EN LOS PAISES DE INSUFICIENTE DESARROLLO}

Los términos productividad, renta, ahorro e inversión están, como hemos visto, correlacionados. El volumen de inversiones, dentro del proceso de formación de capital, es el que mantiene y expande la producción de artículos de consumo y de capitalización. Pero, para que este proceso sea autogenerador, es decir, que en los países de insuficiente desarrollo haya inversiones constantes y crecientes, se requiere la existencia de ahorros suficientes, mercado de capital que los movilice 
y demanda de consumo que estimule la inversión. El aumento en la producción depende así, en los países no desarrollados, del aumento per cápita en las inversiones. La mayor productividad por hora-hombre resultante elevará en esos países la renta, la demanda y el ahorro, estimulando el proceso autogenerador de nuevas inversiones, alcanzándose en esa forma altos niveles de productividad y de progreso para el país. El progreso significa en realidad mayor inversión y ésta mayor ahorro y mayor renta. A mayor renta, menor propensión al consumo y mayor propensión al ahorro, y por consiguiente más inversiones y mayor progreso real.

Cuando el progreso se basa en el proceso autogenerador de formación de capital o sea en la mayor productividad y mayor renta, es un progreso normal que se traduce en aumento en el volumen real de la producción y es distinto del alza artificial de los valores como cuando los aumentos se basan en el alza de precios y permanecen estacionarios o en descenso los volúmenes reales de la producción. Por lo regular, el progreso real es de índole estructural y de largo término, mientras los aumentos de valor a base de alza en los precios son de índole cíclica y temporal que provocan reajustes al terminar el período.

Hemos dicho que la renta nacional proviene de la producción y ésta, a su vez, del volumen de inversiones, de tal manera que para aumentar la producción y la renta hay que aumentar las inversiones.

Veamos qué factores favorecen o retardan el aumento de las inversiones.

El volumen de inversiones puede provenir de dos fuentes: del ahorro voluntario, mediante el proceso autogenerador de formación de capital; y, del llamado «ahorro forzoso», del que nos ocuparemos más adelante.

Los ahorros voluntarios constituyen función directa de la renta real; si la renta real per cápita sube, disminuye la propensión al consumo y aumenta la propensión al ahorro, dando como resultado una mayor diversificación de los ahorros y un aumento en su monto. El fenómeno inverso se produce en el caso de una baja en la renta real.

Hay otros factores también que desalientan al ahorro voluntario, tales como una política fiscal exagerada, o la depreciación progresiva de la unidad monetaria, a causa de una inflación. En ambos casos hay absorción o consumación de ahorros voluntarios y una menor posibilidad de inversión.

Hemos visto ya que uno de los factores que impide en los países poco desarrollados una acumulación de ahorro que haga posible inversiones suficientes, es el promedio per cápita redueido de su renta nacional, así como la desigual distribución de la productividad y renta per cápita en los diferentes sectores de la población y aun en los diversos sectores de una misma industria. Así por ejemplo, en el caso 
de la agricultura en muchos países de América Latina, al lado de la gran propiedad de cultivo intensivo y alto desarrollo técnico de los sectores costeños, hay en la Sierra, la pequeña y gran propiedad que utilizan la lluvia como elemento de riego y cuyos medios primitivos de producción dan una productividad e ingreso per cápita mínimos. La formación de ahorros voluntarios en ese importante sector de consumo subnormal resulta así negativa, concentrándose el ahorro en el sector de mayor productividad, que representa parte relativamente reducida de la población económicamente activa. Ello explica también las diferencias en el nivel de vida y en los ingresos per cápita en las diversas regiones del país. Por eso, una tarea de trascendental importancia es procurar aumentar la productividad y renta de ese amplio sector de la población económicamente activa. En los cuadros respectivos puede apreciarse que el mayor porcentaje de la población económicamente activa está dedicada, en dichos países, a la agricultura y ganadería y que, sin embargo, su ingreso medio per cápita resulta más reducido que el de otros sectores económicos. Se observa también esta diferencia entre los sectores de mayor productividad de la Costa y los de menor productividad y renta de la Sierra. Las irrigaciones y la tecnificación de la agricultura en los sectores atrasados permitirían aumentar el volumen de su producción, de su renta, de su ahorro y de su inversión per cápita; dejando a la vez disponible mayor cantidad de mano de obra para otros fines reproductivos al reemplazarse la fuerza animal por otros tipos de energía. Con formas de producción primitivas en realidad se desperdicia esfuerzo humano y riqueza, continuando la baja productividad y los niveles de renta reducidos en comparación con los de otros países.

Es característica de los países más desarrollados que el volumen de capitales acumulados mediante el ahorro excedan la posibilidad de inversión en el país, procurando entonces su inversión en el extranjero; tal es el caso de los países financieramente acreedores.

En los países de insuficiente desarrollo el fenómeno es inverso: la acumulación de ahorros es insuficiente para atender los requerimientos de nuevas inversiones siendo necesario importar capital que supla esa deficiencia. Ello se explica también por qué el porcentaje de inversiones netas en dichos países es mayor que el que corresponde a reposición; en cambio en los más desarrollados los porcentajes de reposición de las enormes inversiones ya realizadas superan al de las inversiones netas.

En el desarrollo económico de Estados Unidos, por ejemplo, puede apreciarse que hasta antes de la primera guerra mundial ese país fué importador de capital, o sea que sus ahorros internos no abastecieron la necesidad de aumento en las inversiones netas. Igual cosa ha sucedido en el desarrollo histórico de otras naciones. 
Los países menos desarrollados necesitan un mayor volumen de inversiones netas que los más desarrollados tanto por el menor capital invertido como por los enormes fondos que demandan las nuevas explotaciones de los recursos naturales.

En los países más desarrollados para mantener la productividad - aumentarla en un porcentaje normal, se requiere una proporción menor de nuevas inversiones. En cambio, en los países menos desarrollados el porcentaje de aumento en las inversiones netas debe ser mucho mayor para lograr un ineremento en el nivel de productividad.

En los países de poco desarrollo industrial las inversiones dependen de las posibilidades de cambio extranjero y del estado de la balanza de pagos, ya que la mayor parte de artículos de capitalización tienen que importarse por no producirse en el país. Si éste utiliza la moneda extranjera principalmente en gastos de consumo, mermará las posibilidades de inversión, tanto por la falta de moneda extranjera como por el alza que se produciría en el tipo de cambio.

Otro factor que estimula la inversión es la productividad del capital que se invierte. La utilidad constituye la eficiencia marginal del capital invertido; y, las reservas para reposición representan la garantía de la continuación de la actividad económica a pesar del desgaste del equipo de producción. Para estimular la inversión se requiere así que haya utilidad y reservas para reposición. Más adelante veremos qué factores pueden afectar las utilidades o las reservas de reposición, con el desaliento consiguiente de las inversiones. El término inversión se usa en la terminología de la renta nacional, no en el sentido de compra de valores mobiliarios o inmobiliarios, que sólo significan cambio de dinero de una mano a otra, sino de la adquisición de equipo de producción, edificaciones, acumulación de inventarios, etcétera, tal como se ha explicado al tratar de la terminología de la renta nacional. La inversión neta viene a constituir en este sentido adquisición de nuevo equipo productivo en exceso del desgaste normal del equipo de producción existente.

El tipo de interés es de enorme importancia para el estímulo o desaliento de la inversión. Dicho tipo, en una situación económica normal, debe estar en función de la oferta y demanda del mercado de dinero; debiendo, en el caso de una depresión, procurar mantenerlo bajo para estimular las inversiones; y alto en caso de inflación. La política de moneda barata, si bien conveniente en la depresión, resulta inconveniente en la inflación.

El tipo de interés puede estimular o desalentar la inversión, según supere o no la eficiencia marginal del capital, o sea la utilidad obtenida. Si la utilidad obtenida supera lo que se tiene que pagar por el tipo de interés habrá estímulo para la inversión, en el caso contrario habrá desaliento. 
A menudo, el deseo de mantener el capital en forma líquida lleva a operaciones especulativas de corto término, que pagan, por su propia naturaleza, alto tipo de interés, desalentando en esa forma las inversiones reproductivas de largo término en las que no es posible pagar los mismos tipos. En los países poco desarrollados este fenómeno es muy común y es una de las causas principales del poco deseo de inversión del capital privado, que tiende a mantenerse atesorado en forma líquida o dedicado, mediante la actividad comercial bancaria, en transacciones comerciales de corto plazo.

Pero no sólo es el factor de la tasa de interés el que influye en la inversión, sino también diversos factores imponderables. Puede mantenerse artificialmente baja la tasa de interés, pero si no hay confianza, no habrá incentivo de inversión.

Otro factor de enorme importancia para estimular o desalentar la inversión es el sistema impositivo. Si éste es exagerado no sólo puede desalentar nuevas inversiones sino destruir las existentes al impedir la acumulación de reservas para reposición, realizándose así un proceso de autoconsumación del capital invertido, cuyos resultados son de baja en la producción y en la renta real per cápita. Un sistema impositivo sano debe seguir muy de cerca el desarrollo de los costos de producción. Los impuestos ciegos no sólo son contraproducentes sino antieconómicos. No basta por eso el examen en líneas generales de los balances contables sino que debe requerirse información completa sobre los costos de producción y hacer análisis detenido de ellos. En esa forma se evitaría también el grave problema, principalmente en los países atrasados, de la evasión de las cargas fiscales normales. La preponderancia que adquirió en las últimas décadas la teoría del interés de Keynes del «dinero barato» como política permanente ha impedido, en muchos casos, la adopción, en períodos de inflación, de una política restrictiva en las tasas de interés que hubiera atenuado en parte el desarrollo de la inflación en muchos países. Después de la experiencia de los últimos años resultó evidente que si bien una política de dinero barato puede estimular la recuperación en época de depresión, una conveniente alza diferenciada en los tipos de interés que estimule las inversiones reproductivas y desaliente las especulativas, puede resultar, beneficiosa para restringir la inflación.

\section{RELACIÓN ENTRE INVERSIÓN Y DEMANDA}

Para que exista inversión se requiere que haya demanda de los artículos en cuya producción se va invertir. Los siguientes casos principales pueden presentarse: a) Cuando hay desocupación u ocupación deficiente, un aumento en la demanda real, incrementará la producción; b) Cuando hay ocupación plena o inflacción, un aumento 
en la demanda, real o artificial, producirán o acentuarán la inflacción. En los países poco desarrollados el aumento en la demanda acompañado de aumento en la inversión, elevarán la actividad productiva y la renta, ya que la mayor demanda encontrará una mayor producción que la compense.

El incremento en el poder de compra real y en la demanda efectiva estimulan la inversión, en cambio la disminución de la demanda desalienta la inversión porque nadie invertirá si sabe que no hay quien compre los artículos que va a producir. Más adelante estableceremos la diferencia entre incremento en la demanda real y aumento artificial de la demanda. El objetivo de la producción es satisfacer las necesidades del consumo y para que haya consumo se requiere que haya renta. Sin demanda efectiva de consumo no tendría razón de ser la actividad productiva, ya que la producción de mercado es para la venta. La existencia o no de compradores es lo que mantiene, incrementa 0 reduce el volumen de la producción.

La demanda es así función directa de la renta. Si ésta es baja, aquella también lo será, y la producción para la venta interna se encontrará limitada por la insuficiencia del consumo que desalentará nuevas inversiones. La alta renta per cápita de los países más desarrollados hace que la mayor parte de su propia producción se venda en el país. En los Estados Unidos es cerca del $95 \%$ de la producción la que se coloca en el país. Las naciones menos desarrolladas por lo regular dependen de los mercados del exterior para la colocación de sus productos, dependiendo así su situación económica de las fluctuaciones cíclicas de los mercados externos.

Las crisis de depresión en los países más desarrollados se deben, por lo regular, a la carencia de compradores para los artículos que producen, viéndose forzados los productores a disminuir la producción, a aumentar la desocupación y a restringir aún más la demanda real. Más adelante veremos cómo cuando se aleanza la ocupación plena en los países más desarrollados y se pasa por un período de inflación, hay que restringir la demanda en vez de estimularla.

Para que haya mayores ahorros y mayor inversión se requiere que haya mayor renta y mayor producción, y para que pueda haber mayor producción se hace necesario un mayor consumo de los artículos que se produzcan. La mayor inversión para utilizar los recursos naturales improductivos al convertirlos en productivos, elevará la renta y los ahorros permitiendo así amortizar la mayor inversión o realizar con los mayores ahorros nuevas inversiones futuras, estimulando el proceso autogenerador de formación de capital.

Un aumento en la inversión debe venir acompañado del aumento correspondiente en la demanda real mediante el incremento en la renta. De tal manera que habrá equilibrio entre el volumen de ar- 
tículos producidos y su demanda por el público. A este nivel de equilibrio entre la producción y la demanda corresponderá un nivel de precios relativamente estable.

Hay dos clases de demanda: la real, que proviene de un incremento efectivo en la renta per cápita como resultado de una mayor productividad; y la artificial, resultante de emisiones o expansiones inorgánicas de circulante o crédito no acompañadas de incremento real en la producción.

Cuando la demanda, real y artificial, excede el volumen de los artículos producidos, los precios tenderán a subir; si la demanda es inferior a la producción corriente de dichos artículos, los precios bajarán, los stocks aumentarán y la producción tenderá a disminuir.

Para corregir la inflación proveniente de la creación artificial hay, así, que restringir o detener las emisiones inorgánicas y las expansiones artificiales de crédito, hasta que se restablezca el equilibrio entre los artículos producidos y la demanda total. Debe entenderse el término demanda, no sólo como la proveniente de la actividad privada, sino también del Estado, ya que éste puede gastar en artículos de consumo y de inversión y emplear para ello demanda real y artificial.

En los países de mayor desarrollo los niveles de renta, por lo regular, son altos y menor por consiguiente la propensión al consumo, siendo considerable y diversificado el volumen de ahorros. En los de menor desarrollo, la diferencia en el promedio de las rentas y los bajos niveles per cápita de grandes sectores de la población hace que la propensión al consumo sea mayor y menor el volumen de ahorros. Por eso, cuando hay aumento en la demanda de artículos de consumo por expansión monetaria y de crédito, sin que venga acompañada de aumento en la producción, el resultado será un aumento inflacionista de precios.

Puede haber aumento normal en la demanda y, sin embargo, por el atesoramiento y no inversión de los ahorros, la producción no aumente. Normalmente el dinero que se ahorra debe ir a la inversión; pero hay casos en que el ahorro no se invierte en actividades productivas sino se mantiene en forma líquida. Entonces, a pesar de la mayor demanda, no habrá inversiones para la producción de los artículos solicitados y por falta de la producción correspondiente la mayor demanda se convertirá en simple alza de precios.

Para que los precios se mantengan estables debe haber, como hemos dicho, equilibrio entre la demanda y la producción; aunque el equilibrio entre la mayor demanda y la mayor producción puede no producirse en un mismo período sino en períodos sucesivos.

En los países más desarrollados el nivel de equilibrio se alcanza cuando hay ocupación plena. En los menos desarrollados, cuya ca- 
racterística crónica es de «ocupación deficiente» el nivel de ocupación plena en el sentido de los países industrializados es más elástico, ya que por estar poco desarrollados y ser amplios los recursos naturales por explotar la posibilidad de inversiones reproductivas y de aumento consiguiente en la renta, en la demanda, en el ahorro y en la inversión son muchos mayores. Dichas inversiones elevarán el proceso de formación de capital y aumentarán la demanda real y la renta.

Estos países, por su alta propensión al consumo, son precisamente los más expuestos a que un aumento artificial de la demanda, sin la contrapartida de mayor producción, dé lugar a un alza de precios, que disminuya la renta real per cápita, agote los ahorros existentes y dé lugar a una menor producción.

Cuando la renta que perciben los factores de la producción se utiliza en el proceso del cambio o sea se gasta en artículos de consumo y se ahorra, y con dicho ahorro, después, se adquieren artículos de capitalización, ese proceso mantiene estable o incrementa la actividad productiva.

Pero, si en vez de invertirse los ahorros en mayor producción se atesoran en forma líquida, no completa su ciclo el proceso de formación de capital y el resultado es una menor producción y mayores transacciones especulativas de corto plazo. En las formas primitivas de economía y aun durante el mercantilismo, la riqueza estaba constituída por el monto de metales preciosos o dinero que se acumulaba; en la era industrial en que se vive, hay diferencia fundamental entre tesoro y capital. Técnicamente el dinero acumulado sólo se convierte en capital cuando se invierte en la actividad productiva, o sea cuando contribuye al proceso dinámico de formación de capital y producción de mercaderías y servicios. El ahorro voluntario, o sea la renta real retirada del consumo, que no se invierte en la producción, merma la capacidad productiva del país. En muchos casos ello se debe a la falta de organismos de inversión y de mercados de capital que estimulen las inversiones. La banca comercial, por su propia naturaleza, sólo puede cumplir en parte la importante función que en los países más desarrollados cumplen las instituciones de inversión y los mercados de capital. La falta de estos organismos lleva así a una tendencia al atesoramiento.

Entre el valor de la producción y los precios hay relación directa, como la hay entre los precios y la oferta y demanda. Si el volumen de mercaderías aumenta y la demanda baja los precios tenderán a caer; si disminuye la oferta y la demanda aumenta los precios subirán.

Si el volumen de la producción y la demanda real están en equilibrio, los precios permanecerán constantes y habrá estabilidad. En los países desarrollados este nivel se alcanza cuando hay ocupación plena. Si habiendo ocupación plena la demanda aumenta, ello se tra- 
ducirá en simple alza de precios, ya que al no haber mayor producción, la mayor demanda incidirá sobre los artículos disponibles y el resultado será aumento en los precios. La ocupación plena significa así la utilización al máximo posible de los recursos productivos. Cuando hay desempleo, «ocupación deficiente» o utilización insuficiente de los recursos productivos, una mayor inversión significará mayor producción, mayor rental real y mayor progreso, sin que necesariamente se produzca alza inflacionista de precios, ya que la mayor demanda real vendrá precedida de mayor producción. Este caso es de especial importancia para los países de ocupación deficiente.

Un período de prosperidad real se caracteriza: por aumento gradual en la productividad, aumento que normalmente puede ser del 2 al $3 \%$ anual; por una tendencia a la estabilidad en los precios; y aumento gradual en las inversiones, en los ahorros y en las rentas reales per cápita.

Un período de decadencia real y prosperidad ficticia puede caracterizarse por baja o estancamiento en la producción y productividad per cápita; aumento de precios y baja desproporcionada en las rentas reales medidas por el poder adquisitivo; por último, por un proceso de descapitalización de las inversiones y consumación de los ahorros acumulados.

En la economía sólo se puede decir que hay progreso real cuando aumenta la producción y el consumo de los bienes económicos.

En la década del 30 el problema fundamental y dominante fué cómo salir de la crisis de deflación en que había caído el mundo, sobre todo en el período 1930/33. Ello llevó al análisis de las causas de las crisis y a comprobar que la causa principal de la crisis de deflación fué la insuficiencia de la demanda real. Teniendo en cuenta esta situación y principalmente la teoría de Keynes sobre la ocupación plena se adoptaron en los principales países las políticas de recuperación que caracterizaron dicha década.

La década del 40 se ha caracterizado en cambio por la tendencia constante a la inflación en los mercados mundiales, estimulada en alto grado por los gastos bélicos y, en la postguerra, por el deseo de mantener o alcanzar altos niveles de renta, siguiendo la política de «moneda barata».

Todo ello ha dado carácter trascendental en los últimos tiempos al problema de lograr el desarrollo económico con inflación y sin inflación, tema éste que ha sido materia de cuidadoso estudio por casi todos los organismos especializados.

Uno de los temas de mayor interés que se diseutió en la Segunda Reunión de Técnicos de los Bancos Centrales del Continente Ameri- 
cano, que tuvo lugar en la ciudad de Chile en diciembre de 1949, fué la importancia de la política monetaria y las funciones que le corresponden dentro de una política general de estabilidad económica.

En el informe del Vicepresidente Relator de la Comisión C, resumiendo las labores de dicha Comisión, figuran los siguientes párrafos que, por su importancia, reproducimos a continuación:

«Sumamente interesante fueron las discusiones relacionadas con el desarrollo económico y la estabilidad. Se analizaron y discutieron en forma amplia los temas sobre el desarrollo económico con inflación y $\sin$ inflación.

«Se manifestó que mediante planes adecuados de desarrollo económico de largo y corto plazo podía aumentarse la capacidad de producción y el nivel de vida de los países latinoamericanos, realizando programas selectivos de acuerdo con las necesidades económicas básicas.

«Se hizo presente también que, dado el bajo nivel de los ahorros privados en algunos países, la baja en el volumen de la producción, la desfavorable situación de los términos del comercio y el retraimiento en la inversión de capitales, se podía, en ciertos casos, estimular el desarrollo mediante una adecuada acción crediticia. Sin embargo, se destacó la necesidad de evitar en lo posible que esa medida produjese un efecto acelerador del proceso inflacionista, con los consiguientes daños sociales que la inflación origina en la distribución de las rentas.

«A este respecto se estudiaron los casos en que la inflación había dado lugar, en ciertos países, a una considerable baja en el volumen de la producción, impidiendo y detruyendo el proceso normal de formación de capital privado por la falta de reposición y del estímulo para las nuevas inversiones, con la consiguiente consunción del capital invertido. Se analizaron también los casos de otros países en los que el aumento real logrado en algunas ramas de la producción fué, considerado en conjunto, relativamente pequeño y no mayor del aumento normal que se hubiese logrado sin inflación. Por último, se hizo el análisis de aquellos casos en que, dentro de la inflación, se pudo intensificar el proceso de formación de capital, aunque dicho resultado podía haberse debido también en parte, a la acción de otros factores concurrentes como la obtención de préstamos oficiales del exterior y el estímulo que en algunos renglones se dió a la producción.

«Se manifestó que la estabilidad económica no es necesariamente incompatible con el desarrollo económico, y que bien podía realizarse un programa de desarrollo económico ordenado manteniendo a la vez un adecuado nivel de estabilidad». 


\section{EL PROBLEMA DEL AUMENTO EN LA DEMANDA EN LOS PAÍSES}

\section{DESARROLLADOS Y DE MENOR DESARROLLO}

Para que haya progreso real, hemos dicho que debe haber equilibrio entre la oferta y la demanda. Que a mayor inversión, o sea a mayor producción, correspondería mayor renta, mayor consumo y mayor ahorro; o sea, un aumento real en la demanda que estimulará mayores inversiones dando lugar a lo que se conoce con el nombre de proceso autogenerador de formación de capital.

Pero no solamente la demanda puede aumentar por incremento de la demanda real, sino mediante emisión y expansiones inorgánicas del circulante y crédito que incrementarán artificialmente la demanda, sobre todo si no viene acompañada de aumento en la producción sino de incremento en los gastos de consumo. La demanda artificial, no acompañada de mayor producción, al incidir sobre los artículos existentes tiende a producir alza de precios hasta que la oferta y demanda se equilibran a un nivel de precios más alto. Si continúan las emisiones o expansiones inorgánicas de circulante y crédito, ello determinará aumento constante en los precios con las consecuencias del conocido «espiral inflatorio». 